\title{
Description of Culicoides lisicarruni (Diptera: Ceratopogonidae), a new species from Cundinamarca, Colombia
}

\author{
Ligia Moncada ${ }^{1} /{ }^{+}$, María Cristina Carrasquilla ${ }^{2}$, Gustavo Spinelli ${ }^{3}$, Ingrid Lotta ${ }^{4}$, Nubia Matta ${ }^{5}$ \\ ${ }^{2}$ Ministerio de la Protección Social, Bogotá, Colombia ${ }^{3}$ División Entomología, Museo de La Plata, La Plata, Argentina \\ ${ }^{1}$ Departamento de Salud Pública ${ }^{4}$ Maestría de Infecciones y Salud en el Trópico, Facultad de Medicina \\ ${ }^{5}$ Departamento de Biología, Facultad de Ciencias, Universidad Nacional de Colombia, Bogotá, Colombia
}

A new species of Culicoides of the subgenus Diphaomyia Vargas from high altitudes of the Andes in Colombia is described and photographied. The species is compared with its similar congener Culicoides marinkellei Wirth \& Lee. Data on the collecting site and notes on the species daily activity are also provided.

Key words: Culicoides - new species - taxonomy - daily activity - Páramo

Biting midges of the genus Culicoides Latreille are notorious blood-sucking pest of men and animals throughout the world (Wirth et al. 1988). Borkent and Spinelli (2007) recorded 266 from the Neotropical Region and nine species were subsequently described. Seventy of these species are miserable pests of humans and domestic animals and seven of them serve as vectors of a variety of diseases, summarized by Borkent and Spinelli (2007).

Spinelli et al. (2009) reviewed the genus for Colombia, listing 114 species that are known to occur and 66 suspected of being in the country. The purpose of this paper is to describe a new species of the subgenus Diphaomyia Vargas recently collected at the high altitudes of the Chingaza National Natural Park.

\section{MATERIALS AND METHODS}

Specimens were slide mounted in Canada balsam and photographed using a camera Kodak Easy Share C613.

Terms for structures follow those used in the Manual of Nearctic Diptera (McAlpine et al. 1981). Terms for wing veins follow the system in the Manual of Nearctic Diptera, with modifications proposed by Szadziewski (1996). Names of veins are in upper case and those cells in lower case. Pale areas in cell r3 posterior to or immediately distal to second radial cell are called poststigmatic pale spots. Four abbreviated terms are used in the text: antennal ratio (AR) is the combined length of the five distal flagellomeres divided by the combined length of the eight proximal ones; palpal ratio (PR) is the length of the third palpal segment divided by its greatest width; proboscis/head ratio $(\mathrm{P} / \mathrm{H}$ ratio) is the length of the proboscis measured from the distal end of the labrumepipharynx to the anterior margin of the tormae, divided by the distance measured from the anterior margin of the tormae to the median hair socket between the eyes;

Financial support: DIB, Facultad de Medicina/Universidad Nacional de Colombia

+ Corresponding author: limoncadaa@bt.unal.edu.co

Received: 19 June 2010

Accepted: 23 October 2010 costal ratio (CR) is obtained by dividing the length of the costa by wing length, measuring both from the level of the basal arculus of the wing.

\section{RESULTS}

Culicoides lisicarruni Moncada, Carrasquilla, Spinelli sp. nov. (Figs 1-4)

Diagnosis - The only species of the subgenus Diphaomyia with sensilla coeloconica on flagellomeres 1, 9-13 and with two pale spots in cell cua the smaller abutting vein $\mathrm{CuA}_{1}$, while the largest is very narrowly separated from wing margin.

Female - Head (Fig. 1): dark brown. Eyes bare, interocular distance equal to diameter of two ommatidia. Flagellum brown, flagellomeres joints pale, flagellomeres 1-12 bottle-shaped, flagellomere 13 subcylindrical; AR 0.64-0.83 (0.72, $\mathrm{n}=13)$. Sensilla coeloconica on flagellomeres 1, 9-13 $(\mathrm{n}=10)$. On flagellomeres 1,9 and 11 the following number of sensilla is found: flagellomere 1: two sensilla, flagellomeres 9 and 11, one sensillium, flagellomeres 10, 12, 13 variable, as follows: flagellomere 10 and 12: 1-2 sensilla, flagellomere 13: 2-4 sensilla (Fig. 2A). Palpus (Fig. 3) dark brown; third segment subcylindrical, slightly swollen distally with small, round, deep, apical sensory pit; PR 2.5-3.6 (3.09, $\mathrm{n}=12)$; P/H 0.91-1.44 $(1.01, \mathrm{n}=10)$. Mandible with 13-17 teeth $(\mathrm{n}=9)$.

Thorax: scutum, scutellum dark brown. Legs dark brown, fore and midfemora with subapical pale rings, tibiae with subbasal pale rings; hind tibial comb with four spines, first, second spines from spur longest, subequal (Fig. 2B). Wing (Fig. 4) with contrasting pattern; length $1.40-1.70(1.61, \mathrm{n}=11) \mathrm{mm}$; width 0.65-0.96 $(0.72, \mathrm{n}=11)$ $\mathrm{mm}$; CR 0.56; second radial cell in dark spot; one rounded pale spot lying just distal to r-m crossvein; r-m crossvein dark; two small, rounded poststigmatic pale spots in r3 lying slightly obliquely, posterior one not attaining $\mathrm{M}_{1}$; one distal, transverse pale spot in $\mathrm{r}_{3}$ not abutting wing margin nor $\mathrm{M}_{1} ; \mathrm{m}_{2}$ with four small pale spots, basal one lying adjacent to midportion of $\mathrm{CuA}$ stem, other behind pale spot situated posterior to medial fork, other in front to cubital fork, distal one very narrowly separated from wing margin; cua ${ }_{1}$ with two pale spots, smaller abutting 


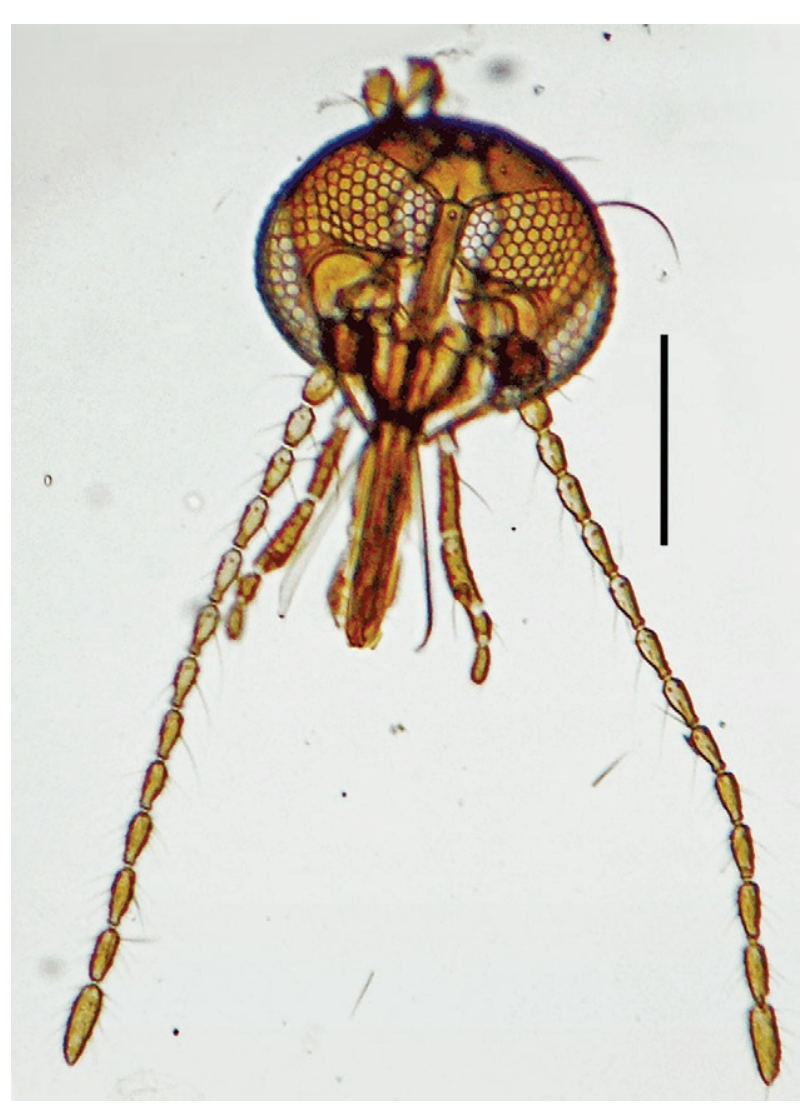

Fig. 1: Culicoides lisicarruni sp. n. head, dorsal view. Bar $=0,1 \mathrm{~mm}$.

$\mathrm{CuA}_{1}$, posterior one very narrowly separated from wing margin; anal cell with two distal pale spots, basal indistinct pale area. Macrotrichia spread on distal 2/3, extending also to base of anal cell. Halter pale brown.

Abdomen: dark brown. Two ovoid, unequal spermathecae with sclerotized necks, measuring 63 by 42 $\mu \mathrm{m}, 59$ by $38 \mu \mathrm{m}(\mathrm{n}=11)$; rudimentary third spermathecae and sclerotized ring present (Fig. 2C).

Male - Unknown.

Type locality - Colombia, Cundinamarca, Chingaza National Natural Park, Monterredondo Station, edge of Babilonia River, 3200 masl.

Type data and depository - Holotype female, Colombia, Chingaza National Natural Park, Monterredondo Station, edge of Babilonia River, 3200 m, 26-II-2009, I. Lotta-R. Gutiérrez, human protected bait, Instituto de Ciencias Natturales (ICN). Paratypes five females, as follows: same data as type, four females (ICN); same data except 27-II-2009, I. Lotta-S. Mantilla, CDC CO2 trap, 1 female (Museo de La Plata).

Distribution - The species is known only from the type-locality.

Binomics - Chingaza Natural National Park is a very extensive area. The maximum temperature at the high altitude area, the Páramo, ranges between $10^{\circ} \mathrm{C}-12^{\circ} \mathrm{C}$,

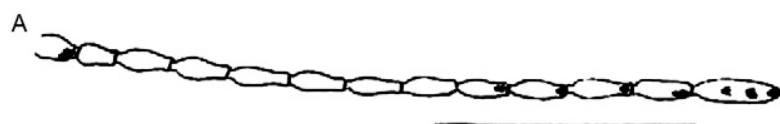

B

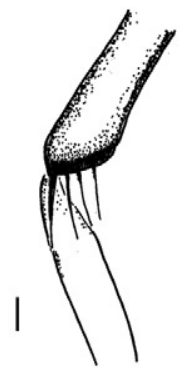

Fig. 2: Culicoides lisicarruni sp. n., lateral view. A: antenna. Bar $=0.25 \mathrm{~mm}$; $\mathrm{B}$ : hind tibial comb. Bar $=0.01 \mathrm{~mm} ; \mathrm{C}$ : spermathecae and sclerotized ring. Bar $=0.025 \mathrm{~mm}$.

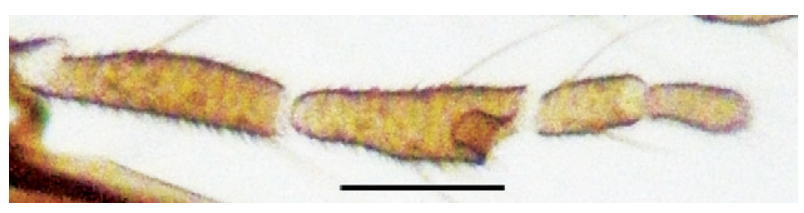

Fig. 3: Culicoides lisicarruni sp. n. palpus, dorsal view. Bar $=0.01 \mathrm{~mm}$.

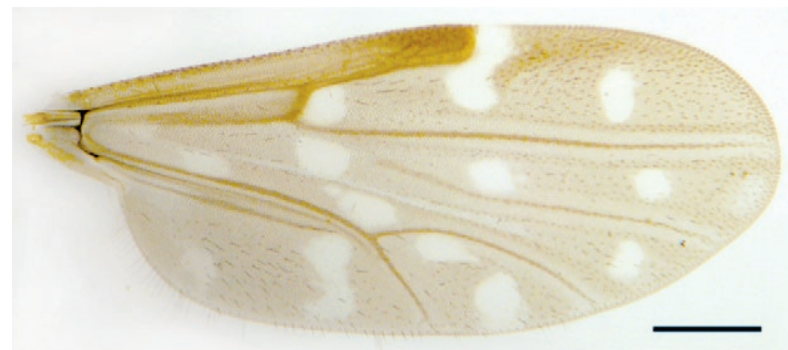

Fig. 4: Culicoides lisicarruni sp. n. wing, dorsal view. Bar $=0.25 \mathrm{~mm}$.

while the minimum between $-2^{\circ} \mathrm{C}-0^{\circ} \mathrm{C}$. The dry season extends from November-March and the rainy one from April-October. C. lisicarruni shows two peaks of activity, one in the daybreak from 06:00-08:00 am and the other during the dusk from 05:00-06:00 pm. Some specimens were observed on a stone as a resting place near the stream where the specimens were collected. Species density was higher during the rainy season.

Etymology - The specific epithet was constructed on the basis of the initials of the first names of the people involved in the specimens collection.

Taxonomic discussion - Considering the new species herein described, the subgenus Diphaomyia Vargas includes 22 species, 11 Neotropical, nine nearctic and two from India (Borkent 2010). Two of the Nearctic species, Culicoides edeni Wirth \& Blanton and Culicoides haematopotus Malloch reach the Neotropics arising to 
14 the number of species inhabiting this biogeographic region, nine of which share the small rounded pale spot lying just distal to r-m crossvein. Of these, Culicoides marinkellei Wirth \& Lee, a species also inhabiting the Colombian Páramo, exhibits a wing pattern almost identical to $C$. lisicarruni, except for the cell cua with only one rounded distal pale spot, lacking the small pale spot lying near the cubital fork.

The presence of two pale spots in cell cua ${ }_{1}$ readily distinguishs $C$. lisicarruni from the remaining species of the subgenus. The distribution of the sensilla coeloconica on flagellomeres 1, 9-13 is only shared by Culicoides freitasi Wirth \& Blanton, but the wing of the later species shows, among other differences, the r-m crossvein entirely covered by a conspicuous rounded pale spot and the cell $\mathrm{m}_{2}$ with a pale spot contiguous to the proximal pale spot in cell $\mathrm{m}_{1}$.

\section{ACKNOWLEDGEMENTS}

To the participants of the Aviar Hemoparasites Group, to the Medical Entomology Laboratory from Colombia National University, to the Administrative Unit of National and Natural Parks, specially to Andrés Patiño, Carlos Lora and Lucía Borrego.

\section{REFERENCES}

Borkent A 2010. The subgeneric classification of the species of $\mathrm{Cu}$ licoides. Thoughts and a warning. [cited 2010 Ap 23]. Available from: http://www.inhs.illinois.edu/research/FLYTREE/CulicoidesSubgenera.pdf.

Borkent A, Spinelli GR 2007. Neotropical Ceratopogonidae (Diptera: Insecta). In J Adis, JR Arias, G Rueda Delgado, KM Wantzen (eds.), Aquatic biodiversity in Latin America (ABLA), vol. IV, Pensoft, Sofia, 198 pp.

McAlpine JF, Peterson BV, Shewell GE, Teskey HJ, Vockeroth JR, Wood DM 1981. Manual of Nearctic Diptera, Agriculture Cana$d a$, vol. I, Monograph 27, Research Branch, Otawa, 674 pp.

Spinelli GR, Santamaría E, Cabrera OL, Ronderos MM, Suárez MF 2009. Five new species of Culicoides Latreille described from Colombia, yielding a new species list and country records (Diptera: Ceratopogonidae). Mem Inst Oswaldo Cruz 104: 81-92.

Szadziewski R 1996. Biting midges from Lower Cretaceous amber of Lebanon and Upper Cretaceous Siberian amber of Taimyr (Diptera: Ceratopogonidae). Stud Dipterol 3: 23-86.

Wirth WW, Dyce AL, Spinelli GR 1988. An Atlas of wing photographs, with a summary of the numerical characters of the neotropical species of Culicoides (Diptera: Ceratopogonidae). Contrib Am Entomol Inst 25: 1-72. 